\title{
ANALISIS PERBEDAAN KEPUTUSAN PEMBELIAN, MOTIVASI DAN PERSEPSI PRODUK BATIK ANTARA KONSUMEN PRIA DAN WANITA DI SURAKARTA
}

\author{
Dwi Oktaviani Lardo Putri ${ }^{1}$ \\ Siti Maryam² \\ Rochmi Widayanti $^{3}$ \\ doktalp@gmail.com ${ }^{1}$ \\ stmuniba17@gmail.com ${ }^{2}$ \\ rochmiwidayanti@gmail.com ${ }^{3}$ \\ Universitas Islam Batik Surakarta
}

Diterima: Mei 2019, Disetujui: Juni 2019, Dipublikasikan: Juli 2019

\begin{abstract}
This study aims to determine differences in purchasing decisions, motivations and perceptions of batik products between male and female consumers in Surakarta.

This type of research uses a comparative descriptive method. The population of this study is the total number of male and female consumers in PGS and Klewer Market which is infinite in number. The sample in this study amounted to 100 respondents (50 PGS respondents and 50 Klewer Market respondents) using nonprobability sampling techniques, namely the purposive sampling method and convenience sampling. Data analysis techniques in this study used the independent sample t test.

The analysis shows that there are significant differences in purchasing decisions and consumer motivation between male and female consumers, but there are no differences in consumer perceptions between male and female consumers.
\end{abstract}

Keyword: Purchase Decision, Consumer Motivation, Consumer Perception, Gender

\begin{abstract}
ABSTRAK
Penelitian ini bertujuan untuk mengetahui perbedaan keputusan pembelian, motivasi dan persepsi produk batik anatara konsumen pria dan wanita di Surakarta.

Jenis penelitian menggunakan metode deskriptif komparatif. Populasi dari penelitian ini adalah keseluruhan konsumen pria dan wanita di PGS dan Pasar Klewer yang jumlahnya tidak terhingga. Sampel pada penelitian berjumlah 100 responden (50 responden PGS dan 50 responden Pasar Klewer) dengan menggunakan teknik pengambilan sampel non probability sampling yaitu metode purposive sampling dan convinience sampling. Teknik analisis data dalam penelitian ini menggunakan uji independent sample $t$ test.
\end{abstract}


Hasil analisis menunjukan bahwa terdapat perbedaan yang signifikan keputusan pembelian dan motivasi konsumen antara konsumen pria dan wanita, namun tidak terdapat perbedaan persepsi konsumen anatara konsumen pria dan wanita.

Keyword: Keputusan Pembelian, Motivasi Konsumen, Persepsi Konsumen, Jenis Kelamin

\section{PENDAHULUAN}

Batik budaya asli dari negara Indonesia memiliki nilai sejarah yang berharga karena itu batik harus dijaga serta dilestarikan, dalam upaya pelestariannya seringkali digunakan untuk berbusana. Produsen batik memiliki alasan disetiap pembuatan desain motif-motifnya, dahulu motif batik dibuat untuk kepentingan penduduk keraton namun seiring berkembangnya zaman batik sudah digunakan oleh semua kalangan dan para produsen batik bersaing dalam menciptakan produk batik ber-kualitas dengan motif yang menjadi ciri khas dari berbagai daerah.

Ketatnya persaingan membuat produsen batik berfikir bagaimana cara untuk mempertahankan pangsa pasarnya karena seiring berkembangnya zaman konsumen menjadi lebih cerdas dalam memilih produk yang akan dibelinya, sehingga perusahaan harus berorientasi pada kebutuhan konsumen dimulai dengan melakukan survey agar dapat mengetahui serta menentukan apa yang diinginkan konsumen, hal tersebut membuat konsumen mengambil keputusan untuk membeli produk dan hasil akhirnya yaitu kepuasan konsumen ( Andespa, 2010:183).

Keputusan membeli suatu prouk biasanya diawali dengan menari informasi terlebih dahulu mengenai produk dan tempat dimana membeli produk itu melalui berbagai media sumber informasi, selanjutnya konsumen melakukan penyaringan berbagai pilihan alternatif produk dan melakukan pembelian produk jika produk sesuai dengan harapan, setelah itu konsumen mengevaluasi produk yang sudah dibelinya jika produk memuaskan maka konsumen akan kembali melakukan pembelian produk tesebut. Keputusan yang diambil oleh konsumen dilatar 
belakangi oleh bermacam faktor seperti lingkungan, sosial dan faktor pribadi (Poluan\&Samadi, 2017:3806)

Motivasi konsumen menjadi salah satu bagian dari faktor pribadi. Motivasi atau dorongan dapat mempengaruhi perilaku seseorang untuk memenuhi kebutuhan dengan melakukan suatu kegiatan membeli produk atau biasa disebut berbelanja, motivasi konsumen yang bersifat pribadi biasanya bertujuan untuk kepuasan diri dan mengikuti trend sedangkan yang bersifat sosial bertujuan untuk dapat berkomunikasi dengan orang lain yang memiliki minat atau keinginan sama, kesenangan tawar menawar harga dan pengalaman sosial diluar rumah (Falode, Amubode \& Adegunwa, 2016: 152)

Motivasi konsumen yang bersifat emosional biasanya memiliki sebuah tujuan untuk mendapatkan perhatian dari orang lain hal tersebut lebih memberi pengaruh terhadap keputusan pembelian konsumen dibandingkan dengan motivasi secara rasional yang membeli produk berdasarkan fungsinya. Selain motivasi, faktor pribadi yang selanjutnya adalah persepsi konsumen (Emine\& Fatma,2016:235236 )

Survei awal yang dilakukan oleh peneliti di lokasi penelitian menemukan bahwa adanya perbedaan perilaku antara konsumen pria dan wanita dalam membeli produk batik, konsumen pria dalam melakukan kegiatan belanja batik sangat cepet ketika dia menemukan yang sesuai segara melakukan transaksi pembelian tanpa mempertimbangkan hal lain, sedangkan konsumen wanita lebih lama saat berbelanja karena memiliki banyak pertimbangan sebelum memilih batik dan melakukan pembelian. Berdasarkan uraian dan latar belakang diatas menjadi pertimbangan peneliti untuk membaha lebih lanjut dan melakukan penelitian mengenai perbedaan keputusan pembelian, motivasi dan persepsi antara konsumen pria dan wanita, dengan ini peneliti berpendapat bahwa layak melakukan penelitian dengan judul : Analisis Perbedaan Keputusan Pembelian, Motivasi Dan Persepsi Produk Batik Antara Konsumen Pria Dan Wanita Di Surakarta. 


\section{TINJAUAN PUSTAKA}

\section{A. Keputusan Pembelian}

Keputusan pembelian merupakan suatu tahapan yang panjang dimana konsumen mengenal masalah, menggali informasi mengenai suatu produk atau suatu merek tertentu dan mengevaluasi alternatif pemecahan masalahnya untuk kemudian mengarah pada pengambilan keputusan pembelian (Fandy Tjiptono 2015:21)

1. Faktor-Faktor Yang Mempengaruhi Keputusan Pembelian.
a. Faktor Lingkungan
b. Faktor Sosial
c. Faktor Pribadi

2. Tahapan-Tahapan Proses Keputusan Pembelian

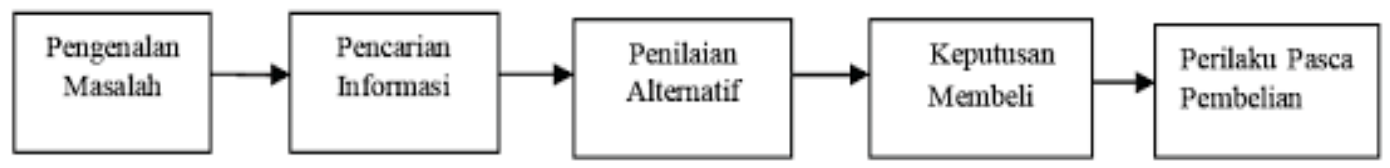

\section{B. Motivasi Konsumen}

1. Pengertian Motivasi Konsumen

Motivasi konsumen adalah suatu tekanan kuat yang mengarahkan seseorang untuk bertindak dengan tujuan mencari kepuasan dengan cara melakukan kegiatan pemenuhan kebutuhannya (Kotler\&Amstrong, 2008:172)

\section{Motivasi Belanja Pria Dan Wanita}

Mulianingsih, Fauzi \& Alfisyah (2019) menyatakan bahwa konsumen wanita lebih memiliki tingkat motivasi belanja hedonis lebih tinggi dibandingkan konsumen pria, dahulu banyak orang mengatakan bahwa wanita lebih sering melakukan aktivitas belanja karena mereka lebih memperhatikan penampilan diri, berbeda dengan kaum pria yang tidak menyukai kegiatan berbelanja bahkan menghindar dari berbagai tempat perbelanjaan yang dianggap terlihat feminim. Gaya pria berbelanja dinilai lebih tegas, tidak ada waktu untuk melihat-lihat produk terlebih dahulu seperti yang dilakukan oleh kaum wanita. 


\section{Persepsi Konsumen}

1. Pengertian Persepsi Konsumen

Hawkins,Mothersbaugh\&Best (2007:282) berpendapat bahwa persepsi konsumen adalah sebuah tahapan proses yang diawali dengan sebuah perhatian terhadap rangsangan pemasaran dan berakhir dengan penafsiran oleh konsumen.

2. Persepsi Belanja Pria Dan Wanita

Konsumen pria kurang memperhatikan resiko pembelian dan kualitas produk karena hanya memikirkan sebatas membutuhkan produk tersebut, lebih mengutamakan manfaatnya saja tanpa memiliki pertimbangan yang lain sedangkan wanita memiliki tingkat persepsi yang tinggi mengenai resiko pembelian, kualitas produk dan kinerja produk hal ini dipengaruhi oleh pengalaman dan pengetahuan yang mereka gunakan untuk mencari alternatif dari banyaknya pilihan produk. (Martiyanti 2015)

\section{Teori tentang pria dan wanita}

Tipe-tipe konsumen berdasarkan jenis kelamin menurut Johnstone 1988, yaitu:

1. Tipe konsumen pria

a. Mudah terpengaruh oleh bujukan penjual.

b. Mudah tertipu karena tidak sabar untuk memilih.

c. Memiliki perasaan tidak enak apabila memasuki toko tanpa membeli sesuatu.

d. Sering terburu-buru saat mengambil keputusan dalam pembelian.

e. Mudah dipengaruhi oleh nasehat yang baik.

2. Cara menanggapi

a. Memberikan pelayanan yang cepat dan tidak rumit

b. Memberikan penjelasan yang terkait saja

c. Mengusahakan agar dia membeli barang yang cocok.

d. Tidak memperlihatkan warna yang menyolok.

3. Tipe konsumen wanita

a. Tidak mudah terbujuk oleh penjual

b. Tertarik pada warna dan bentuknya, tidak pada manfaatnya. 
c. Tertarik pada tren mode.

d. Lebih Mementingkan status sosial.

e. Menyenangi hal-hal bersifat romantis dari pada yang obyektif.

f. Sering meminta saran dari orang lain

g. Memiliki banyak pertimbangan dalam memilih produk

h. Cepat merasakan suasana toko

4. Cara menanggapi:

a. Harus sabarmemberikan perhatian dan jangan cepat tersinggung.

b. Memberikan pelayanan khusus seperti diskon, obral, dll.

\section{METODE PENELITIAN}

Jenis penelitian ini menggunakan metode deskriptif dan komparatif. Populasi dalam penelitian ini adalah seluruh konsumen pria dan wanita di PGS dan Pasar Klewer yang sudah pernah membeli batik untuk dikenakan sendiri yang jumlahnya tidak terhingga dengan menggunakan teknik sampling purposive sampling dan convinience sampling. Sampel yang diambil sebanyak 100 responden. Metode analisis data yang digunakan adalah independent sample $t$ -test.

\section{ANALISA DAN PEMBAHASAN}

\section{A. Analisa Data}

1. Uji Homogenitas

Uji homogenitas pada penelitian ini digunakan untuk menguji apakah konsumen pria dan wanita termasuk dalam sebuah populasi yang homogen Hasil pengolahan data menggunakan program spss versi 21 adalah sebagai berikut: 
Tabel 1

Hasil Uji Homogenitas

\begin{tabular}{|ccc|}
\hline Variabel & Signifikansi & Keteragan \\
\hline Keputusan Pembelian & 0,324 & Homogen \\
Motivasi Konsumen & 0,814 & Homogen \\
Persepsi Konsumen & 0,91 & Homogen \\
\hline
\end{tabular}

Tabel 1 menunjukkan bahwa konsumen pria dan wanita berasal dari populasi yang homogen ( $\mathrm{p}$-value $>0,05)$.

2. Independent sample t-test

Uji independent sample t-test dalam penelitia ini digunakan untuk mencari perbedaan keputusan pembelian, motivasi dan persepsi produk batik antara konsumen pria dan wanita

Tabel 2

Hasil Uji Independent sample t-test

\begin{tabular}{|llcll|}
\hline variabel & t hitung & t tabel & Sig & Keterangan \\
& & & (2- tailed) & \\
\hline $\begin{array}{l}\text { Keputusan } \\
\text { Pembelian }\end{array}$ & 1,999 & 1985 & 0,048 & Ho ditolak \\
Motivasi & 2,184 & 1,985 & 0,031 & Ho ditolak \\
Konsumen & & & & \\
Persepsi & -582 & 1,985 & 0,562 & Ho diterima \\
Konsumen & & & & \\
\hline
\end{tabular}

a. Keputusan Pembelian

Hasil dari pengujian tersebut didapat t hitung sebesar 1,999 lebih besar dari t tabel 1985 signifikan pada 5\% atau (sig 2 - tailed 0,048< 
0,05) maka Ho ditolak yang artinya terdapat perbedaan keputusan pembelian antara konsumen pria dan wanita.

b. Motivasi Konsumen

Hasil dari pengujian tersebut didapat t hitung sebesar 2,184 nilai ini lebih besar dari t tabel 1985 signifikan pada 5\% (sig 2 -tailed $0,031<0,05)$ maka Ho ditolak yang artimya terdapat perbedaan motivasi antara konsumen pria dan wanita.

c. Presepsi Konsumen

Hasil dari pengujian tersebut didapat $t$ hitung sebesar 0,582 lebih kecil dari t tabel 1,985 signifikan pada 5\% (sig 2 tailed 0,562 > 0,05) maka Ho diterima yang artinya tidak terdapat perbedaan persepsi antara konsumen pria dan wanita.

\section{B. PEMBAHASAN}

1. Perbedaan keputusan pembelian produk batik antara konsumen pria dan wanita.

Hasil uji independent sample t-test keputusan pembelian produk batik antara konsumen pria dan wanita diketahui bahwa besarnya nilai t hitung 1,999 > t tabel 1985 signifikan pada 5\% atau (sig 2 - tailed $0,048<0,05)$ maka Ho ditolak yang artinya terdapat perbedaan keputusan pembelian produk batik yang signifikan antara konsumen pria dan wanita di Surakarta. Perbedaan ini terlihat dari keputusan konsumen membeli produk batik, konsumen pria membeli produk batik hanya berfikir mengenai manfaat produknya saja sedangkan wanita sangat memperhatikan detail produk yang sesuai untuk digunakan pada sebuah acara. Hasil ini sejalan dengan penelitian Nisya dan Baidun (2014)

2. Perbedaan motivasi pembelian produk batik antara konsumen pria dan wanita.

Hasil uji independent sample t-test, motivasi pembelian produk batik antara konsumen pria dan wanita diketahui bahwa besarnya nilai $\mathrm{t}$ hitung2,184 > t tabel 1,985 signifikan pada 5\% ( $\operatorname{sig} 2$ - tailed 0,031< 0,05) maka Ho ditolak yang artinya terdapat perbedaan motivasi 
pembelian produk batik yang signifikan antara konsumen pria dan wanita di Surakarta. Konsumen wanita lebih mengutamakan kepuasan pribadi seperti memilih produk batik dengan kain yang berkulitas, tahan lama, model yang sedang trend, motif dan warna yang sesuai keinginan berbeda dengan pria yang mengutamakan manfaat dari produk batik. Hasil ini sejalan dengan penelitian Mulianingsih, Fauzi dan Alfisyah (2019)

3. Perbedaan persepsi produk batik antara konsumen pria dan wanita.

Hasil uji independent sample $t$ test persepsi produk batik antara konsumen pria dan wanita diketahui bahwa besarnya nilai t hitung 0,582 <atatabela1,985 signifikan pada 5\% (sig 2 tailed 0,562>0,05) maka Ho diterima yang artinya tidak terdapat perbedaan persepsi produk batik antara konsumen pria dan wanita di Surakarta. Konsumen pria dan wanita menganggap batik memiliki motif unik, memiliki corak yang menjadi pembeda dengan produk busana lainnya, menganggap batik memiliki warna yang beragam dan menganggap batik adalah busana yang sering dipakai untuk acara-acara formal. Hasil ini sejalan dengan penelitian Ardiana dan Basuki (2015)

\section{KESIMPULAN}

\section{A. KESIMPULAN}

1. Terdapat perbedaan yang signifikan variabel keputusan pembelian antara konsumen pria dan wanita di Surakarta. Konsumen pria membeli produk batik hanya berfikir mengenai manfaat produknya saja sedangkan wanita sangat memperhatikan detail produk yang sesuai untuk digunakan pada sebuah acara.

2. Terdapat perbedaan yang signifikan variabel motivasi antara konsumen pria dan wanita di Surakarta. Konsumen wanita lebih mengutamakan kepuasan pribadi seperti memilih produk batik dengan kain yang berkulitas, tahan lama, model yang sedang trend, motif dan warna yang sesuai keinginan berbeda dengan pria yang mengutamakan manfaat dari produk batik. 
3. Tidak terdapat perbedaan yang signifikan variabel persepsi antara konsumen pria dan wanita di Surakarta. Konsumen pria dan wanita menganggap batik memiliki motif unik, memiliki corak yang menjadi pembeda dengan produk busana lainnya, menganggap batik memiliki warna yang beragam dan menganggap batik adalah busana yang sering dipakai untuk acara-acara formal.

\section{B. SARAN}

Saran yang dapat diberikan penulis sehubungan dengan hasil penelitian ini adalah sebagai berikut:

1. Diharapkan produsen batik yang ada di PGS dan Pasar Klewer lebih memperhatikan lagi apa yang diminati oleh konsumen baik pria maupun wanita, mulai dari model, motif dan warna yang harus selalu mengikuti perkembangan zaman.

2. Diharapkan produsen mampu menciptakan lagi motif dan warna busana batik yang dapat dipandang berbeda antara konsumen pria dan wanita.

\section{REFERENSI}

Andespa, Roni.2010.Hubungan Perbedaan Gender Terhadap Keputusan Dalam Membeli Produk Pakaian Jadi.Riau: Jurnal Ekonomi dan Bisnis.Vol.1,No.2:182-191.academia.edu

Ardiana,Nafila Syahbani dan Sugeng Basuki.2015. Pengaruh Merek Dan Persepsi Konsumen Terhadap Keputusan Pembelian Di Toko Online Adorable Projecs.Jurnal Aplikasi Bisnis.Vol.1.no.1:1120.jab.polinema.ac.id

Falode, Bukola, Adetoun Amubode dan Mojisola Olanike.2016.Online and Offline Shopping Motivation of Apparel Consumers in Ibadan Metropolis, Nigeria.International Journal of Marketing Studies.Vol.8,no.1:150-160

Hawkins, Del, David Mothersbaugh dan Roger Best.2007.Consumer Behavior: Building Marketing Strategy. New York: McGraw Hill Company Inc.

Koca, Emin dan Fatma Koc.2016.A Study of Clothing Purchasing Behavior By Gender With Respect To Fashion And Brand Awareness .Turkey: European Scientific Journal.Vol.112,No.7:234-248.eujournal.org Kotler, Philip dan Gary Amstrong.2008.Principles of Marketing, 12 Edition, Jilid 1 Terjemahan Bob Sabran.Jakarta: Erlangga 
Martiyanti, Dwi.2015.Perbedaan Gender Mengenai Perceived Risk Pada Pembelian Online.Samarinda:Jurnal Ekonomi Bisnis.Vol.12,no.2:140149. journal.feb.unmul.ac.id

Nisya,khoirun dan Baidun Akhmad.2013.Faktor Yang Mempengaruhi Konsumen Terhadap Keputusan Membeli Busana Muslimah Modern.Journal of Psychology.Vol.2.No.1:119-136

Mulianingsih, Defi, Achmad Fauzi dan Rizal Alfisyahr.2019.Pengaruh Motivasi Belanja Hedonis Terhadap Kecenderungan Pembelian Impulsif Di Online Shop Jurnal Administrasi Bisnis.Vol.66.No.1:56-66.

administrasibisnis.studentjournal.ub.ac.id

Poluan, Jane dan Reitty Samadi.2017.Analisis Faktor Pembedaan Keputusan Membeli Pakaian Di Freshmart Bahu Manado.Jurnal Ekonomi Menajamen Bisnis dan Akuntansi.Vol.5,No.3:3804-3814 ejournal.unsrat. .ac.id 